\author{
Asian Journal of \\ Medical and Biological Research \\ ISSN 2411-4472 (Print) 2412-5571 (Online) \\ www.ebupress.com/journal/ajmbr
}

\title{
Review \\ Ethnomedicinal, phytochemical and pharmacological properties of Piper longum (Linn)
}

\author{
Hakim Md. Osman gani ${ }^{1 *}$, Md. Obydul Hoq ${ }^{2}$ and Tahmina Tamanna ${ }^{2}$ \\ ${ }^{1}$ Hamdard Unani Medical College and Hospital, Betgari, Banani, Sajahanpur, Bogra, Bangladesh \\ ${ }^{2}$ Hamdard University Bangladesh, Gazaria, Munshiganj-1510, Bangladesh
}

*Corresponding author: Hakim Md. Osman gani, Hamdard Unani Medical College and Hospital, Betgari, Banani, Sajahanpur, Bogra, Bangladesh. E-mail: osmangani1974@gmail.com

Received: 04 March 2019/Accepted: 21 March 2019/ Published: 31 March 2019

\begin{abstract}
Herbs orchestrate resurgence and vegetal awakening is supervened everywhere in the world. Medicinal plants always played an important role in the health development of mankind. Piper longum provides us new lead molecules for the development of drugs against various pharmacological targets. Plants included in this family are annual and persistent herbs or shrubs, indigenous to northern moderate stretch of the world. Piper longum is well known for its medicinal and pharmaceutical importance. In this review studies we will want to explore the various pharmacological properties of Piper longum in Unani system of medicine. Evidence suggests that various listed of Unani Medicine formulated with the Piper longum among these few are tablet, capsule, syrup and semi-solid etc. The primary constituents isolated from various parts of $P$. longum are piperine, piperlongumine, sylvatin, sesamin, diaeudesmin piperlonguminine, pipermonaline, and piperundecalidine. It is most commonly used to treat chronic bronchitis, asthma, constipation, gonorrhea, paralysis of the tongue, diarrhea, cholera, chronic malaria, viral hepatitis, respiratory infections, stomachache, bronchitis, diseases of the spleen, cough, and tumors. This study provides detailed information about the $P$. longum fruit, including phytochemistry, pharmacological profile and safety profile.
\end{abstract}

Keywords: Piper longum; antimicrobial potential; pharmacological activities; phytochemistry; unani medicine

\begin{abstract}
1. Introduction
Plants play a major role in the discovery of new therapeutic agents. They have received a lot of attention during these days for the isolation of biologically active substances for the cure of diseases. Plant based medicinal compounds is long established to be used as traditional treatment for innumerable human diseases from time immemorial in many parts of the world. It is still the primary source of medicine in rural areas of the developing countries (Chitme et al., 2004). About $80 \%$ of the population in developing countries uses traditional medicines for their health related problems (Kim, 2005). Biologically active compounds derived from medicinal plants have been the basis for the development of new chemical leads for the pharmaceutical industry. Evidences shows that out of the 500000 plant species occurring worldwide, only $1 \%$ has been phytochemically investigated, which shows that the medicinal plants has a great potential for discovering novel bioactive compounds (Palombo, 2011). The urge for plant based herbal compounds as an alternative prevention and treatment method comes from increasing number of health issues as well as the increased resistance gained by pathogenic bacteria to currently used chemotherapeutics, infections in immune-compromised individuals and financial concerns in developing countries (Tichy and Novak, 1998; Badria and Zidan, 2004). Many plantderived compounds have been used as drugs, either in their original or semi-synthetic form. Piper longum or Pipali which was mostly used for household cooking purposes as a spice and as seasoning now is a component of medicine as attested by several studies. It is reported as good remedy for treating gonorrhea, menstrual pain, tuberculosis, sleeping problems, respiratory tract infections, chronic gut-related pain and arthritic conditions
\end{abstract}


(Mehta et al., 1998). Since a long time $P$. longum has been used to possess immunomodulatory and antitumor activity (Courageot et al., 2000). Pharmacological and clinical studies have revealed that piperine, a compound isolated from $P$. longum act as CNS depressant, antipyretic, analgesic, anti-inflammatory (Ratner et al., 1991), antioxidant (Wakade et al., 2008), and possess hepatoprotective activities (Gurumurthy et al., 2012a). In addition piperine has also shown to enhance the bioavailability of several drugs, for example sulfadiazine, tetracycline, streptomycin, rifampicin, pyrazinamide, ionized, thambutol, and phenytoin (Van der Westhuizen et al., 1980). Considering its significant effect on the bioavailability enhancing capability of drugs, it has potential to be used as an adjuvant with therapeutic drugs in chronic ailments, to reduce the effective dose of the drug intake thus reducing the subsequent adverse effects (Nagatome et al., 2005).

\section{Vernacular names}

Sanskrit: Pippali, Magadhi, Kana, Usana, etc.

English: Indian long pepper, Long pepper

Hindi: Pipal, Pipli,

Gujarati: Lindipipal, Pipli

Marathi: Pimpli

Bengali: Pipul, Pipli

Malyalam: Pimpli, Tippali, Magadhi, Lada, Mulagu,

Punjabi: Maghs- pipal, Pipal, Filfildaras, Drafilfil.

Telagu: Pippallu, pipili, Pippali katte.

Tamil: Pippili, Tippili, Kundan, tippili, Sirumulam, Pippallu.

Arabian: Dra-filfil.

Persi: Filfilidray, Pipal, Filfil-i-daras.

Santhal: Ralli

Urdu: Pipul (Ayurvedic Pharmacopoeia of India, 2001)

\section{Taxonomic classification}

Kingdom: Plantae

Division: Magnoliophyta

Class: Magnoliopsida

Order: Piperales

Family: Piperaceae

Genus: Piper

Species: longum

Botanical name: Piper longum (Kirti and Basu, 1980)

\section{Plant description}

$P$. longum is a small shrub with a large woody root and numerous creeping, jointed stems that are thickened at the nodes. The leaves are alternate, spreading, without stipules and with blades varying greatly in size. The lowest leaves are 5-7 cm long, whereas, the uppermost are $2-3 \mathrm{~cm}$ long. Flowers grow in solitary spikes. The fruits, which grow in fleshy spikes $2.5-3.5 \mathrm{~cm}$ long and $5 \mathrm{~mm}$ thick, are oblong, blunt, and blackish-green. The mature spikes are collected and dried as the commercial form of pippali, and the root radix is known as pippalimula. There are three grades of piplamul: grade I with thick roots and underground stems fetch a higher price than grade II or III, which consist of thin roots, stems, or broken fragments. The commercial drug consists almost entirely of transversely cut pieces (length, 5-25 mm; diameter 2-7 mm), which are cylindrical, straight, or slightly curved; some have distinct, swollen internodes exhibiting a number of leaf and rootlet scars. The surface is a dirty light brown. The drug has a peculiar odor and a pungent bitter taste that produces numbness on the tongue (Rastogi and Malhotra, 1993).

\section{Geographical distribution}

The plant grows in evergreen forests of India and is cultivated in Assam, Tamil Nadu, and Andhra Pradesh. Long pepper (Figures 1 and 2) is cultivated on a large scale in limestone soil and in heavy rainfall areas where relative humidity is high. 


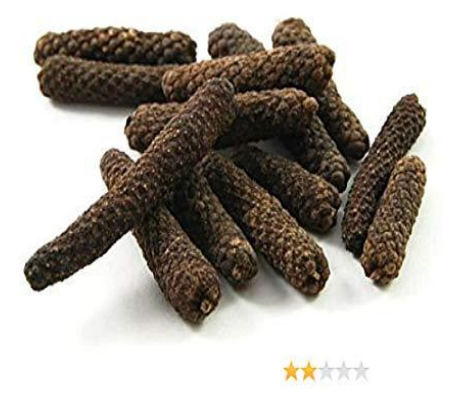

Figure 1. Fruits of Piper longum.

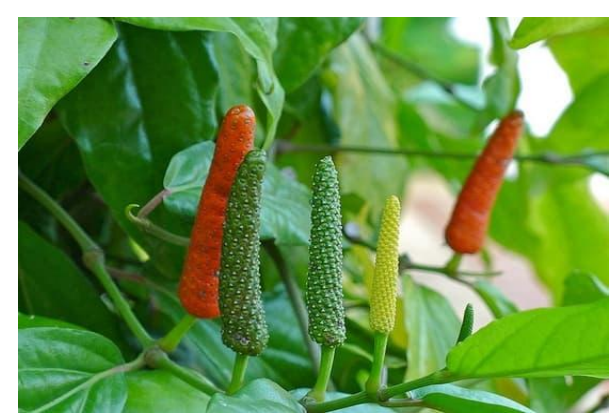

Figure 2. Leaf with fruits of Piper longum.

6. Parts used: Fruits and roots.

\section{Chemical profile}

The fruit contains a large number of alkaloids and related compounds, the most abundant of which is piperine, followed by methyl piperine, pipernonaline, piperettine, asarinine, pellitorine, piperundecalidine, piperlongumine, piperlonguminine, retrofractamide A, pergumidiene, brachystamide- $\mathrm{B}$, a dimer of desmethoxypiplartine, $\mathrm{N}$-isobutyl decadienamide, brachyamide-A, brachystine, pipercide, piperderidine, longamide, dehydropipernonaline piperidine, and tetrahydro piperine. Piperine, piperlongumine, tetrahydropiperlongumine, trimethoxy cinnamoyl-piperidine, and piperlonguminine have been found in the root. Newly identified chemical constituents are 1-(3_,4_-methylenedioxyphenyl)- 1E-tetradecene, 3-(3_,4_methylenedioxophenyl)- propenal, piperoic acid, 3_,4_-di-hydroxy-biabola-1, 10-diene, eudesm-4(15)-ene1beta, 6-alpha-diol, 7-epi-eudesm-4(15)-ene-1beta, 6beta-diol, guineesine, and 2E,4E dienamide, (2E, 4E, 8E) Nisobutylhenicosa- 2,4,8-trienamide. The main lignans present in the fruits are sesamin, pulviatilol, and fargesin. The fruits contain tridecyl-dihydro-p-coumarate, eicosanyl-(E)-p-coumarate, and Z-12octadecenoicglycerol- monoester. The essential oils of the fruit are a complex mixture. Excluding the volatile piperine, the three major components are caryophyllene, pentadecane (both about 17.8\%), and bisaboline (11\%). Others include thujone, terpinolene, zingiberene, p-cymene, pmethoxyacetophenone, dihydrocarveol, and vitamins A and E. The major organic acids present are palmitic acid and tetrahydropiperic acid (Dutt et al., 1975).

\section{Unani description}

Unani Name / Tibbi Name: Fil Fil daraj

Scientific name: Piper longum (Linn)

Mijaz (Temperament): $2^{\text {nd }}$ degree hot and dry

Maza (Taste): Bitter

Boo (Odour): Acrid

Dosage: $2.5 \mathrm{gm}$ to $5 \mathrm{gm}$.

Nafa-e-Khas (Special action): Stomach and Balgham (Phlegm) related diseases.

\section{Important unani formulations}

Some important unani formulations of $P$. longum are as follows:

Syrup kurchi

ARQ Faulin

Capsule Mumsik

Tablet Azaraqi

Tablet Munish

Majoon Lana

Majoon Falasefa

Majoon Sohag Soonth

Jowarish Jalinoos (BNUF, 2010)

\section{Ethnomedicinal uses}

The root and stem part of the P. longum, has been used for various Ayurvedic and Unani system of medicine. The fruits of the $P$. longum are used as a stomachic, liver tonic, aboartifacient, pungent, aphrodiasic, stomachic, 
laxative, anti-diarrhoeal, anti-dysenteric, anti-asthmatic, antibronchitis, abdominal complaints, in urinary discharges, tumours, diseases of the spleen, pains, inflammation, leprosy, insomnia, jaundice, and hiccoughs. The roots of $P$. longum are used for the management of heart diseases. An infusion of the root is used for parturition, to assist in the expulsion of the placenta. It appears to part take, in a minor degree of the stimulant properties of the fruit and also used as an alternative tonic in paraplegia, chronic cough, enlargement of the spleen and other abdominal viscera. $P$. longum has been used in a variety of compositions of drugs; boiled with ginger, mustard oil, butter milk and curds. It forms a liniment, used in case of paralysis. The roasted fruits of $P$. longum are beaten up with honey and given to treat rheumatism. The decoction of dried young fruits and root are of P. longum used in the form of decoction in the treatment of acute and chronic bronchitis (Parmar et al., 1997).

\section{Pharmacological profile}

This plant has gained attention for its therapeutic value in last few years. The ripe fruit of $P$. longum has been widely used as popular medicine to treat a number of diseases some of which are listed below.

\subsection{Anti-tumor activity}

A study showed the effect of piperine and piplartine on Sarcoma 180 tumors transplanted in mice where they observed significant reduction of tumor weight in piplartine- and piperine-treated animals (Bezerra et al., 2006). Another study proved the antitumor activity of piperine is related to its immunomodulatory properties, which involve the activation of cellular and humoral immune responses. The anti-tumor properties of piperine marks it as a potential candidate for future cancer therapy (Sunila and Kuttan, 2004).

\subsection{Anti-diabetic activity}

The anti-diabetic activity of Piper longum has been elucidated the anti-hyperglycemic and anti-hyperlipidemic effects of Piper longum root aqueous extract (PlrAqe) in streptozotocin (STZ) induced diabetic rats. Their studies envisages that the plant extract is capable of managing hyperglycemia and complications of diabetes in STZ induced diabetic rats making this plant as one of the potential sources for the isolation of new oral antihypoglycemic agents (Nabi et al., 2013).

\subsection{Cardioprotective}

Chauhan observed the cardioprotective effect of methanolic extract of $P$. longum (MePl) in a rat model having acute myocardial infarction, induced by Isoproterenol. The MePl extract used was in crude form and likely to contain compounds such as alkaloids and amides, lignans, esters and volatile oil. They propounded that MePl significantly prevents the damage induced by isoproterenol on histopathological and biochemical changes in rat model of myocardial infarction (Chauhan et al., 2010).

\subsection{Hepatoprotective activity}

Gurumurthy experimented with aqueous extract of fruits of $P$. longum and piperine were chosen to study their hepatoprotective potential on administration with normal doses of anti-tubercular drugs. $P$. longum and piperine on administration with the anti TB drugs lowered the rate of lipid peroxidation and also increased the reduced glutathione levels and thus exhibits hepatoprotective effect (Gurumurthy et al., 2012b).

\subsection{Anti-apoptosis}

Yadav illustrated the anti-apoptosis and antioxidant activity of $P$. longum through TUNEL ASSAY and Radical scavenger activity (DPPH ASSAY). They evaluated the effect of hexane: ethanol (2:8) P. longum extract on GM-induced hair cell loss in basal, middle and apical regions in a neonatal cochlea cultures. An anti-apoptosis effect and potent radical scavenger activity of subfraction PL extract protects from GMinduced hair cell loss at basal, middle and apical regions in neonatal cochlea cultures (Yadav et al., 2014).

\subsection{Anti-microbial}

Scientist tested the antibacterial and antifungal activity of various solvent extract of $P$. longum against a variety of pathogenic bacteria and fungi respectively. According to Singh and Rai $P$. longum can be promising source of antimicrobial agents where it could be used against certain antibiotic resistant specific bacteria, besides their use as traditional spice (Singh and Rai, 2013). 
11.7. Anti-inflammatory and Anti-arthritic activity

According to Stohr Piper extracts and piperine possess inhibitory activities on prostaglandin and leukotrienes COX-1 inhibitory effect and thus exhibit anti-inflammatory activity (Stohr et al., 2001). On the other hand Yende studied anti-arthritic effect of $P$. longum in CFA (Complete Freund's adjuvant) induced arthritis in rats where they illustrated that the aqueous extract of $P$. longum has the capability to significantly reduce the swelling of the paws which may be attributed to the immunomodulatory activity exhibited by piperine (Yende $e t$ al., 2010).

\subsection{Respiratory disorders}

For centuries this spice is used as a medicine to cure diseases related to the lungs and respiratory system. An extract of the fruits in milk reduced passive cutaneous anaphylaxis in rats and protected guinea pigs against antigen-induced bronchospasm (Kulshresta et al., 1971).

\subsection{Antioxidant activity}

$P$. longum exhibits promising antioxidant potential against free radical-induced oxidative damage. Petroleum ether extract of the root and piperine from roots of $P$. longum Linn. decrease lipid peroxide levels and maintain glutathione content, demonstrating antioxidant activity (Natarajan et al., 2006).

\subsection{Immunomodulatory activity}

The specific and nonspecific immune-stimulatory actions of $P$. longum fruits have been evaluated by hemagglutination titer, macrophage migration index, and phagocytic index in mice. A well-known Ayurvedic preparation containing long pepper (Pippali rasayana) was tested in mice infected with Giardia lamblia and found to activate macrophages, as shown by an increased macrophage migration index and phagocytic index, indicating immune-stimulatory activity (Tripathi et al., 1999).

\subsection{Antidepressant activity}

Ethanol extraction of $P$. longum fruits yields a known piperidine and piperine alkaloid, as a monoamine oxidase inhibitor. Thus the piper longum fruits represent a promising pharmacotherapeutic candidate against depression (Lee et al., 2008).

\subsection{Antiamoebic activity}

The fruits were tested for their efficacy against Entamoeba histolytica in vitro and against experimental cecal amebiasis in vivo. The ethanol extract and isolated piperine improved cecal amebiasis by $90 \%$ and $40 \%$, respectively, in rats (Ghoshal and Lakshmi, 2002).

\section{Interactions}

Moderate interaction. Be cautious with this combination-

- Phenytoin (Dilantin) interacts with $P$. longum

Indian long pepper might increase how much phenytoin (Dilantin) the body absorbs. Taking $P$. longum along with phenytoin (Dilantin) might increase the effects and side effects of phenytoin (Dilantin).

- Propranolol (Inderal) interacts with P. longum Indian long pepper might increase how much propranolol (Inderal) the body absorbs. Taking P. longum along with propranolol (Inderal) might increase the effects and side effects of propranolol (Inderal).

- Theophylline interacts with $P$. longum

Indian long pepper can increase how much theophylline the body absorbs. Taking theophylline along with $P$. longum might increase the effects and side effects of theophylline.

\section{Contraindication}

Pippali should never be given with Anti-coagulants and beta blocker-propranolol because it increases effect of these drugs which causes dangerous consequences.

\section{Side effect}

Usage of Pippali in some may lead to burning sensation of hands, foot or burning eye syndrome in some patients. Long use of it is harmful for heart and also causes headache. Charak has also mentioned to avoid inappropriate use of Pippali. 


\section{Conclusions}

Although the results from this review are quite promising for the use of Withania somnifera as a multi-purpose medicinal agent, several limitations currently exist in the current literature. While Ashwagandha has been used successfully in Unani and Ayurvedic medicine for centuries, more clinical trials should be conducted to support its therapeutic use. It is also important to recognize that Withania somnifera may be effective not only in isolation, but may actually have a potentiating effect when given in combination with other herbs or drugs.

\section{Acknowledgements}

The authors acknowledge the inspired provided by Dr. Alhaj Hakim Md. Yousuf Harun Bhuyan, honorable chief mutaowalli and managing director, Hamdard Laboratories (Waqf) Bangladesh and Lt. colonel Mahbubul Alam chowdhury (Ret:), honorable director, Hamdard Foundation Bangladesh , for the preparation of this manuscript.

\section{Conflict of interest}

None to declare.

\section{References}

Ayurvedic Pharmacopoeia of India, 2001. Ministry of Health and Family Welfare, S Govt of India, 1st Edition, Dept of Indian Science of Medicine and Homeopathy, New Delhi, Controller of Publication Civil Lines, Volume-4 part-1 pp. 1-170.

Badria FA and OA Zidan, 2004. Natural products for dental caries prevention. J. Medi. F., 7: 381-384.

Bangladesh National Unani Formulary (BNUF), 2010.

Bezerra DP, FO Castro, APNN Alves, C Pessoa, MO Moraes, ER Silveira, MAS Lima, FJM Elmiro and LV Costa-Lotufo, 2006. In vivo growth-inhibition of Sarcoma 180 by piplartine and piperine, two alkaloid amides from Piper. Braz. J. Med. Biol. Res., 39: 801-807.

Chitme HR, M Chandra and S Kaushik, 2004. Studies on anti-diarrhoeal activity of Calotropis gigantea R.Br. in experimental animals. J. Pharm. Pharm. Sci., 7: 70-75.

Courageot MP, PM Frenkiel, CD Dos-Santos, V Deubel and P Desprès, 2000. Alpha-glucosidase inhibitors reduce dengue virus production by affecting the initial steps of virion morphogenesis in the endoplasmic reticulum. J. Virol., 74: 564-572.

Chauhan K, L Parmar, R Solanki and V Kagathara, 2010. Effect of Piper longum linnon histopathological and biochemical changes in isoproterenol induced myocardial infarction in rats. RJPBCS., 1: 760.

Dutt CP, N Banerjee and DN Roy, 1975. Lignans in the seeds of Piper longum. Phytochem., 14: 2090-2091.

Gurumurthy P, S Vijayalatha, A Sumathy, M Asokan and M Nassema, 2012a. Hepatoprotective effect of aqueous extract of Piper longum and piperine when administered with antitubercular drugs. The Bioscan., 7 : 661-663.

Gurumurthy P, S Vijayalatha, A Sumathy, M Asokan and M Nassema, 2012b. Hepatoprotective effect of aqueous extract of Piper longum and piperine when administered with antitubercular drugs. The Bioscan., 7: 661-663.

Ghoshal S and V Lakshmi, 2002. Potential antiamoebic property of the roots of Piper longum Linn. Phytother. Res., 16: 689-691.

Kim HS, 2005. Do not put too much value on conventional medicines. J. Ethnopharmacol., 100: 37-39.

Kirti KR and BD Basu, 1980. Indian medicinal plants. Mumbai, India: Orients Longman, 1980: 21-28.

Kulshresta VK, N Singh, RK Shrivastava, RP Kohli and SK Rastogi, 1971. A study of central stimulant activity of Piper longum. J. Res. Indian Med., 6: 17-19.

Lee SA, JS Hwang, XH Han, C Lee, MH Lee, SG Choe, SS Hong, D Lee, MK Lee and BY Hwang, 2008. Methylpiperate derivatives from Piper longum and their inhibition of monoamine oxidase. Arch. Pharm. Res., 31: 679-83.

Mehta A, N Zitzmann, PM Rudd, TM Block and RA Dwek, 1998. Alphaglucosidase inhibitors as potential broad based anti-viral agents. FEBS Lett., 430: 17-20.

Nagatome Y, Y Hirayama and T Ito, 2005. Effects of tea containing Hihatu (Piper longum) extract on cold constitution. J. Pharmacol. Sci., 97: 115.

Nabi SA, RB Kasetti, S Sirasanagandla, TK Tilak, MVJ Kumar and CA Rao, 2013. Antidiabetic and antihyperlipidemic activity of Piper longum root aqueous extract in STZ induced diabetic rats. BMC Compl. Altern. Med., 13: 37. 
Natarajan KS, M Narasimhan, KR Shanmugasundaram and ER Shanmugasundaram, 2006. Antioxidant activity of a salt/ spice/herbal mixture against free radical induction. J. Ethnopharmacol., 105: 76-83.

Palombo EA, 2011. Traditional medicinal plant extracts and natural products with activity against oral bacteria: Potential application in the prevention and treatment of oral diseases. Evi. Compl. Alt. Med., 2011: 1-15.

Parmar V, S Jain, K Bisht, R Jain, P Taneja, A Jha, O Tyagi, A Prasad, J Wengel, CE Olsen and PM Boll, 1997. Phytochemistry of the genus Piper. Phytochem., 46: 597-673.

Ratner L, N vander Heyden and D Dedera, 1991. Inhibition of HIV and SIV infectivity by blockade of alphaglucosidase activity. Virology, 181:180-192.

Rastogi RP and BN Malhotra, 1993. Compendium of Indian Medicinal Plants. CDRI, Luckhnow and New Delhi, India. pp.504-857.

Sunila ES and G Kuttan, 2004. Immunomodulatory and antitumor activity of Piper longum Linn. and piperine. J. Ethnopharmacol., 90: 339-346.

Singh C and NP Rai, 2013. In vitro anti-bacterial activity of Piper longum L. Fruit. Int. J. Phar. Sci. Rev. Res., 18: 89-91.

Stohr JR, PG Xiaso and R Bauer, 2001. Constituents of Chinese piper species and their inhibitory activity on prostaglandin and leukotriene biosynthesis in vitro. J. Ethnopharmacol., 75: 133-139.

Tichy J and J Novak, 1998. Extraction, assay, and analysis of antimicrobials from plants with activity against dental pathogens (Streptococcus sp.). J. Alt. Compl. Med., 4: 39-45.

Tripathi DM, N Gupta, V Lakshmi, KC Saxena and AK Agrawal, 1999. Antigiardial and immunostimulatory effect of Piper longum on giardiasis due to Giardia lamblia. Phytother. Res., 13: 561-565.

Wakade AS, AS Shah, MP Kulkarni and AR Juvekar, 2008. Protective effect of Piper longum L. on oxidative stress induced injury and cellular abnormality in adriamycin induced cardiotoxicity in rats. Indian J. Exp. Biol., 46: 528-533.

Van der Westhuizen JH, D Ferreira and DG Roux, 1980. Phytochemical deoxygenation of a ketol: the dihydroflavonol-flavanone conversion. J. Chem. Soc. Perkin. Trans., 1:1003-1006.

Yadav MK, J Choi and JJ Song, 2014. Protective effect of hexane and ethanol extract of Piper longum L. on Gentamicin- induced hair cell loss in neonatal cultures. Clin. Exp. Otorhinolaryngol.. 7: 13-18.

Yende SR, VD Sannapuri, NS Vyawahare and NH Uday, 2010. Antirheumatoid activity of aqueous extract of Piper longum on freunds adjuvant-induced arthritis in rats. Int. J. Pharm. Sci. Res., 1: 129-133. 